\title{
Quantifying Uncertainty Propagation For The District Energy Demand Using Realistic Variations On Input Data
}

\author{
Ina De Jaeger ${ }^{1,2,3}$, Glenn Reynders ${ }^{1,3}$, and Dirk Saelens ${ }^{1,2}$ \\ ${ }^{1}$ EnergyVille, Thor Park 8310, BE-3600 Genk \\ ${ }^{2}$ KU Leuven, Department of Civil Engineering, Building Physics Section, Kasteelpark Arenberg 40 \\ - box 2447, BE-3001 Heverlee \\ ${ }^{3}$ Flemish Institute for Technological Research (VITO), Boeretang 200, BE-2400 Mol
}

\begin{abstract}
The optimal design and operation of district energy systems highly depends on an accurate quantification of the district energy demand. However, a significant uncertainty arises due to the large amount of input data that is required to quantify the energy demand of existing districts. To assess the uncertainty propagation, QuasiMonte Carlo simulations are applied to a residential district of 350 dwellings to generate 99 samples of every dwelling. The mean uncertainty of the district energy demand and the uncertainty on the mean district energy demand both decrease as the district size increases. Moreover, a preliminary sensitivity analysis indicates that the transmission losses are the most dominant parameters and should be gathered as accurately as possible when modelling existing districts.
\end{abstract}

\section{Introduction}

District energy simulations (DES) are often proposed to evaluate and plan energy efficiency and renewable energy measures towards a more sustainable building stock. Bottom-up DES quantify the district level energy demand of buildings by simulating and aggregating the individual buildings within the district. The district energy demand in dimensions of time and space serves as an important boundary condition for optimal design and operation of district energy systems (Mavromatidis et al., 2018).

In order to quantify the energy demand of all buildings within an existing district, a significant amount of input parameters are required for every building. These include characteristics regarding geometry and location, occupant behaviour, building envelope, heating, ventilation and air conditioning (HVAC) systems, renewable energy systems, and building appliances. Although these characteristics could be acquired per building, the data acquisition effort becomes infeasible on district or city level. As a result, highly detailed and accurate input data are rarely available on district level, introducing a significant uncertainty on the energy demand within DES.

An accurate estimation of the impact of input data uncertainty on the simulated district energy demand is critical for the interpretation of DES and for the trustworthiness of conclusions based on these simulations. Therefore, this work focuses on quantifying uncertainty propagation for the energy demand from building level to district level.
Although they are not yet standard practice, many uncertainty analyses (UAs) and sensitivity analyses (SAs) have been performed in building energy simulations (Clarke \& Hensen, 2015). An elaborate overview of UAs and SAs respectively can be found in (Tian et al., 2018) and (Tian, 2013). The UA and SA results within building energy simulations highly depend on the considered set of uncertain parameters, but they generally stress the importance of including both thermo-physical and occupant-related characteristics (Mastrucci et al., 2017).

On district level, the simulation outcome is even more subject to uncertainty due to the lack and/or the questionable quality of available data. However, opposed to the building level, UAs and SAs are rarely considered on district level due to their high computational cost. Naber et al. (2017) reviewed how uncertainties are handled in building stock models and concluded that if uncertainty is considered, it is most often by comparative testing and rarely through a SA.

Since the study of uncertainty is important to assess the trustworthiness of DES, this work addresses the influence of input data uncertainty on the district energy demand for space heating and identifies the main driving parameters for the uncertainty, while studying different district sizes. This work focuses on modelling existing districts, and does not intend to study the optimal design of new districts. It investigates how the uncertainty propagation changes from building level to district level for existing districts and analyses how the uncertainty on the district energy demand evolves while the district size increases. To this end, a global sensitivity analysis is performed for 350 dwellings of the residential Boxbergheide district in the City of Genk, Belgium. As this work is considered as a first step in revealing the most influencing building envelope and occupancy parameters, a regression-based $\mathrm{SA}$ is selected thanks to its simplicity. In its final form, it may serve as a guideline on how to reduce existing - often significant - discrepancies between measured and modelled district energy use.

In the next Section, the concepts of UA and SA in the context of building and district energy simulations are introduced. Subsequently, the methods used for the uncertainty and sensitivity analyses in this work are explained, along with the studied district. In the fourth Section, the uncertainty on the energy demand for space heating is first presented on the building level and then on the district level. Additionally, the results of the 
sensitivity analysis are shown for an increasing district size. Then, the implications of the established analysis for future work are discussed. Lastly, conclusions are drawn.

\section{UA and SA in building and district energy simulations}

UAs and SAs are related, but their focus differs. UAs focus on assessing the output uncertainty caused by the input uncertainty, whereas SAs concentrate on assessing how the different inputs contribute to the output uncertainty. Often, a UA is first presented, followed by a SA. Numerous methods exist to perform UAs (MonteCarlo sampling-based, non-sampling, non-probabilistic) and SAs (local, global). The workflow for most prevalent methods within building energy simulations is introduced now, yet this summary is non-exhaustive.

The first step in both UA and SA consists in defining the uncertain parameters and their variations. Defining the input variations is difficult and depends on the purpose of the study (Tian, 2013). For example, with regard to the physical parameters, normal distributions can be most suited when monitoring the energy consumption whereas uniform distributions are better suited to identify the optimal design of a particular building.

After defining the input variations, specific samples need to be drawn from these distributions following a specific sampling method. The sampling method also depends on the selected sensitivity analysis method, as some sensitivity analysis methods (e.g. Sobol', FAST, Morris) require specific sampling schemes. If a specific sampling scheme is not required (e.g. regression-based SA), then the Monte Carlo method is generally used for sampling. However, multiple sampling options exist within Monte Carlo analyses. The traditional Monte Carlo method uses random sampling to generate its samples (Metropolis \& Ulam, 1949). In order to improve the convergence rate of the results, Latin Hypercube sampling (Mckay et al., 1979) and optimised Latin Hypercube (Johnson et al., 1990) are often used. As an alternative, Quasi-Monte Carlo methods can be used, generating low discrepancy sequences (e.g. Sobol', Niederreiter) to improve the convergence rate of the results even more.

After the samples are drawn, the building energy models are generated and simulated. On district level or larger, simplified building energy models are often used due to the high computational cost. As an example, Hughes et al. (2015) employed the quasi-static calculation method SAP to perform their sensitivity analyses. Also, Nouvel et al. (2017) performed a comparative analysis to assess the influence of data quality on the urban heat demand quantification through the use of a quasi-static calculation method, included in Simstadt (Nouvel et al., 2015).

At this point, the resulting uncertainty can be quantified through numerical indicators (e.g. mean, median, mode, interquartile range) or visualised (e.g. histograms, density plots, box plots) (Tian et al., 2018).

Additionally, a global or a local SA can be performed. A local SA analyses the impact of one parameter at a time, whereas a global SA explores the whole parameter space. The global SAs can be subdivided in the following categories: regression-based methods, variance-based methods (e.g. Sobol', FAST), screening-based methods (Morris) and meta-model-based methods (Tian, 2013). In regression-based SAs, multiple measures can be used as sensitivity indices (e.g. standardised regression coefficients, partial correlation coefficients, Spearman rank correlation coefficients). Based on the specific purpose and the available computational power, a proper SA method should be selected.

\section{Methods}

In this Section, first the studied district is introduced. Subsequently, all steps in the uncertainty and sensitivity analysis are presented.

\section{Introduction to the case study}

In order to quantify the uncertainty propagation, a district of 350 single-family dwellings in the Boxbergheide district in the City of Genk, Belgium, is studied. For this district, a CityGML model with level of detail (LOD) 2 (Gröger \& Plümer, 2012) is available, containing the building geometry and location. In this model, the number of storeys and their heights for every building are unknown and need to be estimated. Therefore, the maximum number of storeys with a height of $3 \mathrm{~m}$ that fit within the ridge height of the building is calculated. Then, this number of storeys is used to calculate the actual storey heights. Additionally, the construction year is acquired for every building of the district based on a visual survey (Callebaut \& Saelens, 2018).

\section{Input variations and sampling}

In this work, the focus is on building envelope and occupancy parameters for which realistic variations are determined based on building geometry and construction year, using a recently developed quantile regressionbased method (De Jaeger, Lago, \& Saelens, 2018a). The variations intend to be realistic within the context of simulating existing districts. The selected input parameters for the uncertainty analysis can be divided in three categories:

- building geometry (ground floor area, façade area, roof area, heated volume, window-to-wall ratio (WWR), inner floor area and inner wall area),

- building envelope (infiltration rate, U-value of the ground floor, U-value of the outer wall, Uvalue of the roof and U-value of the windows) and

- building occupant (number of occupants, specific occupant profile).

As a result, 14 parameters are varied. Their distributions are shown in Table 1 and discussed below. Most of the geometry-related parameters (i.e. ground floor area, façade area, roof area and heated volume) are assumed to have a low uncertainty, as they originate from the LOD2 CityGML model. Nevertheless, the accuracy of the LOD2 

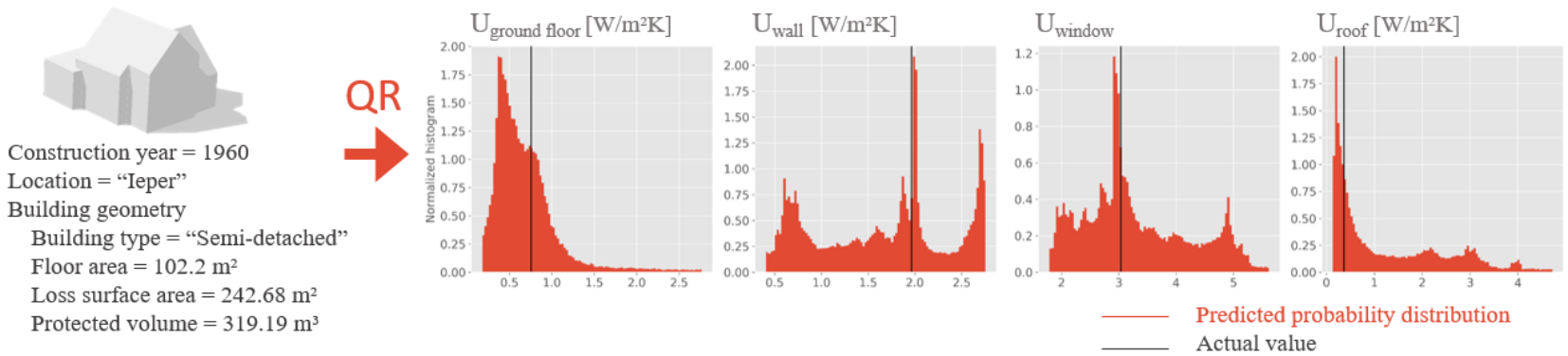

Figure 1: Illustration of the probabilistic characterisation method for a building belonging to the test set of the EPC database (De Jaeger et al., 2018a). Based on the input characteristics, a probability distribution is estimated for each $d w e l l i n g$ and each parameter individually (WWR is not shown here). The grey line indicates the real value for this dwelling, as it appears in the EPC database.

model is unknown and consequently, the distribution is assumed normal around the value obtained from the CityGML model with a standard deviation of $5 \%$. The window area is not included in the LOD2 model and needs to be estimated. To this end, a probabilistic characterisation method that was recently developed by De Jaeger et al. (2018a) is used. This method employs quantile regression to estimate the WWR, along with the $\mathrm{U}$-value of roofs, outer walls, windows and ground floors, based on the building geometry, location and construction year. The method is illustrated in Figure 1. The models are trained based on the Flemish Energy Performance Certificates database. Energy Performance Certificates are labels that inform consumers of the energy efficiency of buildings they plan to purchase or rent. The Flemish Energy Performance Certificates (EPC) database is therefore a valuable resource for energy performancerelated data of buildings (i.e. building type, construction year, building geometry, thermal performance of the building envelope, information on the HVAC systems, ...). Finally, the uncertainty on the inner floor area and the inner wall area, on the other hand, is assumed to be larger, as they are based on assumptions. The inner floor area initially depends on the assumed number of storeys. The inner wall area is initially assumed to be equal to the outer wall area. Both parameters are characterised by a uniform distribution between 0.5 and 1.5 times the initial assumption.

Except for the infiltration rate, all envelope-related parameters (U-value of roofs, outer walls, windows and ground floors) are estimated based on the probabilistic characterisation method that is introduced above. Unfortunately, the infiltration rate is rarely measured for the dwellings of the EPC database and is therefore not included in the method. As an alternative, a distribution is fitted on 50 pressurisation tests in old (both original and renovated) dwellings. These measurements were carried out within the context of three VLAIO pilot projects for renovation in Flanders. The best fit is found to be lognormal, characterised by a mean of 2.619 , a standard deviation of 0.451 and shifted to the left over 0.708 .

No occupant-related info is available for the studied district. Therefore, data on the household sizes for Flanders (Wonen Vlaanderen, n.d.) are used, resulting in a Gamma distribution, with the shape parameter equal to 3.525 and the scale parameter equal to 0.656 . In this work,
1919 stochastic user behaviour were generated, using the StROBe package, as explained in the next Subsection. After sampling the number of occupants, a specific profile is allocated, corresponding to the number of occupants.

After defining the input variations, specific samples need to be drawn from these distributions following a specific sampling method. As a regression-based sensitivity analysis is performed, the Monte Carlo method is used to generate samples. Although multiple sampling methods exist, a Sobol' sequence (Sobol', 1967) is selected in this work and generated for 14 parameters and 99 samples, resulting in 34650 building simulations.

Table 1: Overview of the uncertainty parameters and their distribution. The distributions are specified as Norm(mean, standard deviation), Uniform(min, max), Lognormal(standard deviation, shift, mean) and Gamma(shape, scale).

\begin{tabular}{|c|c|}
\hline Parameter & Distribution \\
\hline \multicolumn{2}{|l|}{ Building geometry } \\
\hline Ground floor area & $\begin{array}{l}\text { Normal }(1.0,0.05) * \text { value from } \\
\text { the LOD2 CityGML model }\end{array}$ \\
\hline Façade area & $\begin{array}{l}\text { Normal }(1.0,0.05) * \text { value from } \\
\text { the LOD2 CityGML model }\end{array}$ \\
\hline Roof area & $\begin{array}{l}\text { Normal }(1.0,0.05) * \text { value from } \\
\text { the LOD2 CityGML model }\end{array}$ \\
\hline Heated volume & $\begin{array}{l}\text { Normal }(1.0,0.05) * \text { value from } \\
\text { the LOD2 CityGML model }\end{array}$ \\
\hline WWR & Quantile regression model \\
\hline Inner floor area & $\begin{array}{l}\text { Uniform }(0.5,1.5) * \text { value from } \\
\text { "own assumption" }\end{array}$ \\
\hline Inner wall area & $\begin{array}{l}\text { Uniform }(0.5,1.5) * \text { value from } \\
\text { "own assumption" }\end{array}$ \\
\hline \multicolumn{2}{|l|}{ Building envelope } \\
\hline Infiltration rate & Lognorm $(0.451,-0.708,2.619)$ \\
\hline U-value ground floor & Quantile regression model \\
\hline U-value outer wall & Quantile regression model \\
\hline U-value roof & Quantile regression model \\
\hline U-value windows & Quantile regression model \\
\hline \multicolumn{2}{|l|}{ Building occupant } \\
\hline Number of occupants & $\operatorname{Gamma}((3.525,0.656)$ \\
\hline Specific profile & $\begin{array}{l}\text { Uniform }(0.0,1.0) * \text { number of } \\
\text { available profiles for the selected } \\
\text { number of occupants (1919 in } \\
\text { total) }\end{array}$ \\
\hline
\end{tabular}




\section{Generation and simulation of building energy models}

Subsequently, building energy models - including stochastic occupant behaviour - are automatically created and simulated using the IDEAS Modelica library through the use of TEASER and StROBe. These software environments are introduced hereafter.

The original version of the open-source Python package TEASER (Remmen et al., 2018) imports a CityGML model, containing the building geometry, building function and construction year, enriches these data with material layers for all building elements based on the German TABULA project and exports Aixlib or IBPSA Modelica models. However, the TEASER version used in this work is slightly adapted to the needs of this analysis. Firstly, to simplify the sample generation, an additional import feature is implemented, more in particular import from a csv-file. The csv-file contains the same data as the available CityGML file, but considers only eight possible orientations for the building elements (N, NE, E, SE, S, $\mathrm{SW}, \mathrm{W}$ and $\mathrm{NW}$ ) and only one tilt for all the pitched roof parts of a particular building. These simplifications improve the simulation time significantly with a negligible loss in accuracy (De Jaeger et al., 2018b). Secondly, the data enrichment is based on the probabilistic characterisation method as described by De Jaeger et al. (2018a). Thirdly, stochastic occupant profiles are generated via StROBe and allocated to the different buildings. Finally, the export of detailed two-zone models to the IDEAS Modelica library is implemented (De Jaeger et al., 2018b).

The Python package StROBe (Baetens \& Saelens, 2015) provides functions to generate stochastic user behaviour profiles for residential dwellings. These profiles include the mass flow rate of DHW tapping, the internal heat gains (convective and radiative separately), the use of electrical appliances and the temperature set-points for different zones in a building (day zone, night zone and bathroom). They are based on data from the Belgian Time Use Survey of 2005, the Belgian Household Budget Survey of 2005 and the Dutch Qualitative House Registration survey of 2000.

The IDEAS Modelica library supports detailed building energy simulations modelling transient thermal phenomena within the building using a zonal modelling approach, assuming perfect mixture of the air inside the zone. A detailed description of the IDEAS library is given by Jorissen et al. (2018). The adapted TEASER version is used to generate two-zone IDEAS building models, assuming that the ground floor represents the day zone while all upper storeys belong to the night zone. As the focus of this study is on the energy demand for space heating, each building is implemented with an ideal radiator heating system. As most dwellings are constructed before 2000, no mechanical ventilation system is included. To calculate the ventilation losses, air infiltration is considered, but window opening is not. The simulations are conducted for the heating dominated climate of Uccle (Belgium) for a period of 1 year. A 1month initialization period is used. Simulations are performed in Dymola, using the Dassl solver with an output interval of $10 \mathrm{~min}$. After generating the building energy models, they are automatically simulated and analysed within Python. This work only focuses on the annual energy demand for space heating for both building and district level.

\section{Aggregation from building to district level}

Since the focus is on the district energy demand, districts are composed based on single buildings. Districts of different sizes (1 to 349) are generated based on the following method. This method is also illustrated in Figure 2. For each district size (e.g. 2), 349 randomly selected district samples are considered, i.e. unique sets of dwellings that are part of the district (e.g. district consists of 'dwelling A' and 'dwelling B'). For each dwelling within a particular district sample 99 samples are simulated to represent the distributions of the input parameters for each of the dwellings. Therefore, multiple samples of this district sample - building samples - can be considered. In this work, 99 samples of each district samples are considered, based on a random and unique selection of the individual building samples. As a result, 34551 unique districts are considered per district size.

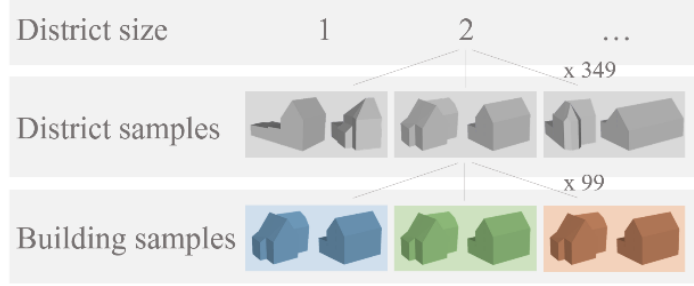

Figure 2: Visual overview of the method to compose districts from single buildings and their 99 samples.

\section{Uncertainty and sensitivity analysis}

After composing the districts based on single buildings, the resulting uncertainty on the district energy demand is quantified. In this work, the uncertainty for each of the district samples is calculated following Equation (1):

$$
u_{D S}=P_{90}-P_{10} / \bar{E}_{B S}
$$

where $u_{D S}$ is the uncertainty of the district sample, $P_{90}$ is the $90^{\text {th }}$ percentile of the district energy demand of all 99 building samples, $P_{10}$ is the $10^{\text {th }}$ percentile of the district energy demand of all 99 building samples and $\bar{E}_{B S}$ is the mean district energy demand of all 99 building samples.

Subsequently, the uncertainty for each of the district sizes is calculated following Equation (2):

$$
u_{D S I}=\bar{u}_{D S}
$$

where $u_{D S I}$ is the uncertainty of the district size and $\bar{u}_{D S}$ is the mean of the uncertainties of all 349 district samples within this district size. The resulting uncertainties are presented for different district sizes in the next Section.

Additionally, to identify the uncertainty source for the different district sizes, a regression-based sensitivity analysis is performed. In order to select a proper sensitivity index, the scatter plots are assessed first. Since they show a nonlinear relationship, the Spearman rank correlation coefficient (SRCC) is selected as a sensitivity index. The SRCC is the rank transformation of the 


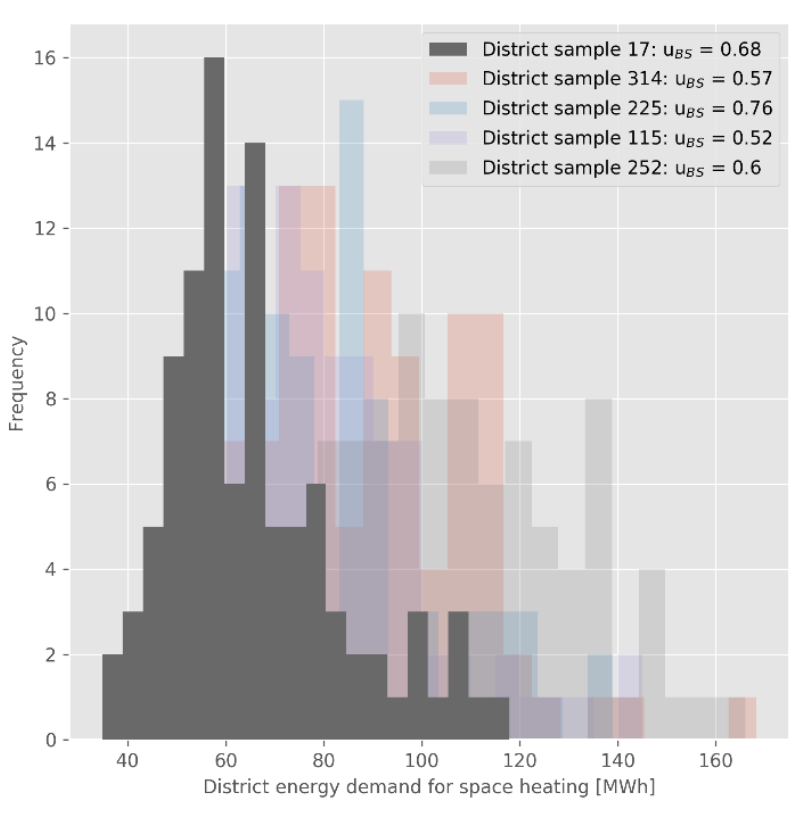

Figure 3: Histogram of the district energy demand of five different district samples for districts containing two dwellings (based on 99 building samples of each district sample).

Pearson product-moment correlation coefficient (PMCC) (Hamby, 1994). The rank transformation not only linearizes monotonic nonlinear relationships between inputs and output, but also reduces the effects of outliers (Hamby, 1994). As a result, the SRCC only measures the degree of monotonicity between the inputs and the output. It is calculated using the PMCC formula (Equation (3)), after the rank transformation:

$$
r_{x y}=\frac{\sum_{i=1}^{n}\left(x_{i}-\bar{x}\right)\left(y_{i}-\bar{y}\right)}{\sqrt{\sum_{i=1}^{n}\left(x_{i}-\bar{x}\right)^{2}} \sqrt{\sum_{i=1}^{n}\left(y_{i}-\bar{y}\right)^{2}}}
$$

where $r_{x y}$ is the correlation coefficient between variables $\mathrm{x}$ and $\mathrm{y}, n$ is the sample size, $x_{i}$ and $y_{i}$ are the individual sample points of variables $\mathrm{x}$ and $\mathrm{y}$ respectively and $\bar{x}$ and $\bar{y}$ are the mean values of variables $\mathrm{x}$ and $\mathrm{y}$ respectively.

\section{Results}

In this Section, to check how the uncertainty evolves as the district scale increases, the uncertainty for different district sizes is presented first. Then, the ranking of the different input parameters according to the SRCC is shown for different district sizes, to assess from where the uncertainty originates and how it changes if the district scale increases.

\section{Uncertainty analysis}

First, the uncertainty is illustrated for two district sizes (2 and 300 buildings). Then, the uncertainty is quantified for more district sizes. In general, a decreasing uncertainty on the district energy demand for space heating is noted as the district size increases. The uncertainties on the different parameters start to neutralise each other if the district size increases.

Figure 3 shows the variability on the district energy demand of a district consisting of two dwellings, for five district samples randomly selected from 350 different

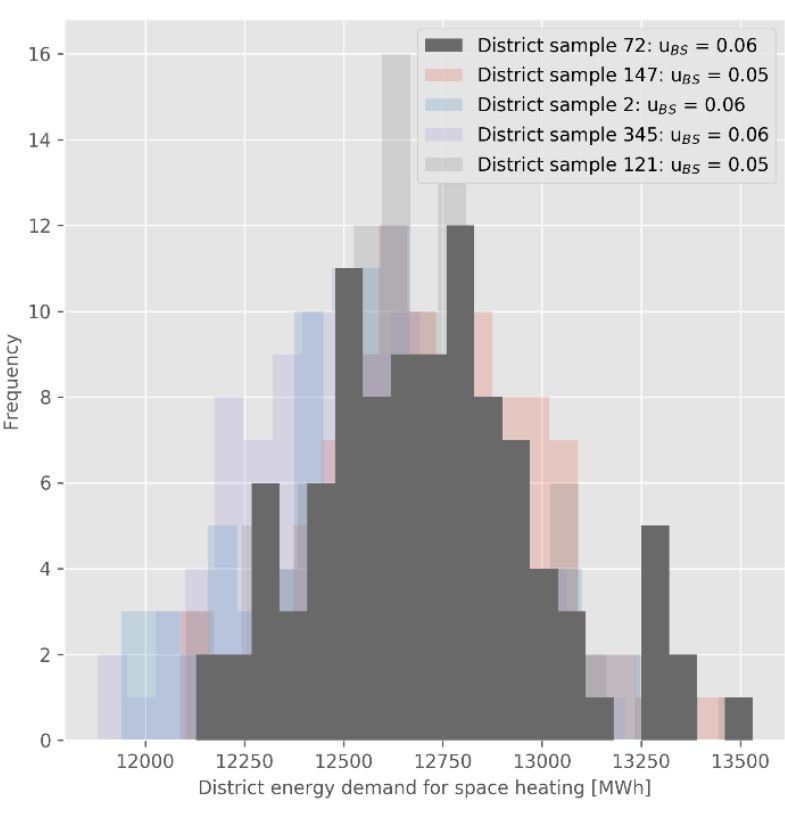

Figure 4: Histogram of the district energy demand of five different district samples for districts containing 300 dwellings (based on 99 building samples of each district sample).

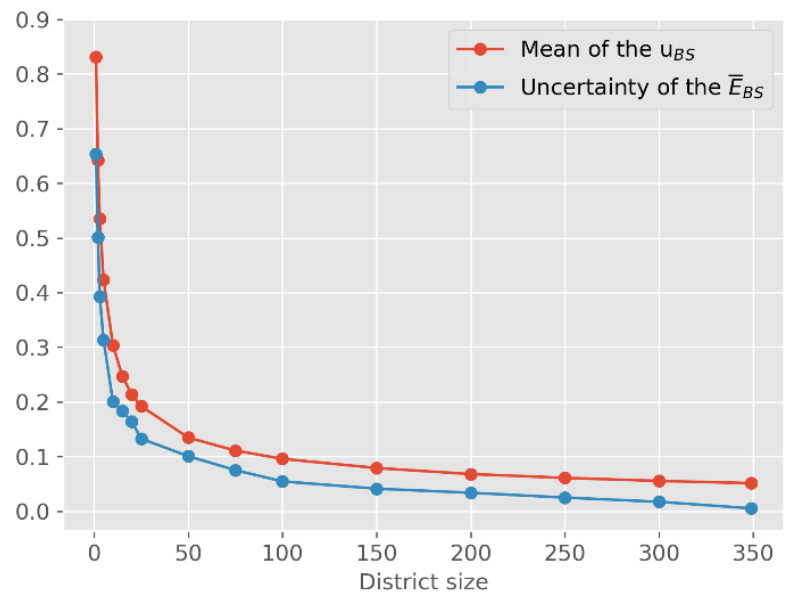

Figure 5: The mean uncertainty on the district energy demand of all district samples within one district size is shown in red. The uncertainty of the mean district energy demand of all 349 district samples within one district size is shown in blue.

buildings. The displayed distribution for each district sample consists of 99 variations of the two buildings that are part of this district sample. The uncertainty for these five district samples is around $60 \%$. Moreover, the mode (i.e. the most occurring value) differs from district sample to district sample, as illustrated by the peaks of the different colours. Figure 4 shows the variability on the district energy demand of a district consisting of 300 dwellings, again for five district samples. The uncertainty for these five district samples is around 6\%. Additionally, the mode of the five different district samples is more similar than in the case of two buildings. Comparing both figures for small and large district size exemplifies how uncertainty on the district energy consumption decreases for increasing district size. 

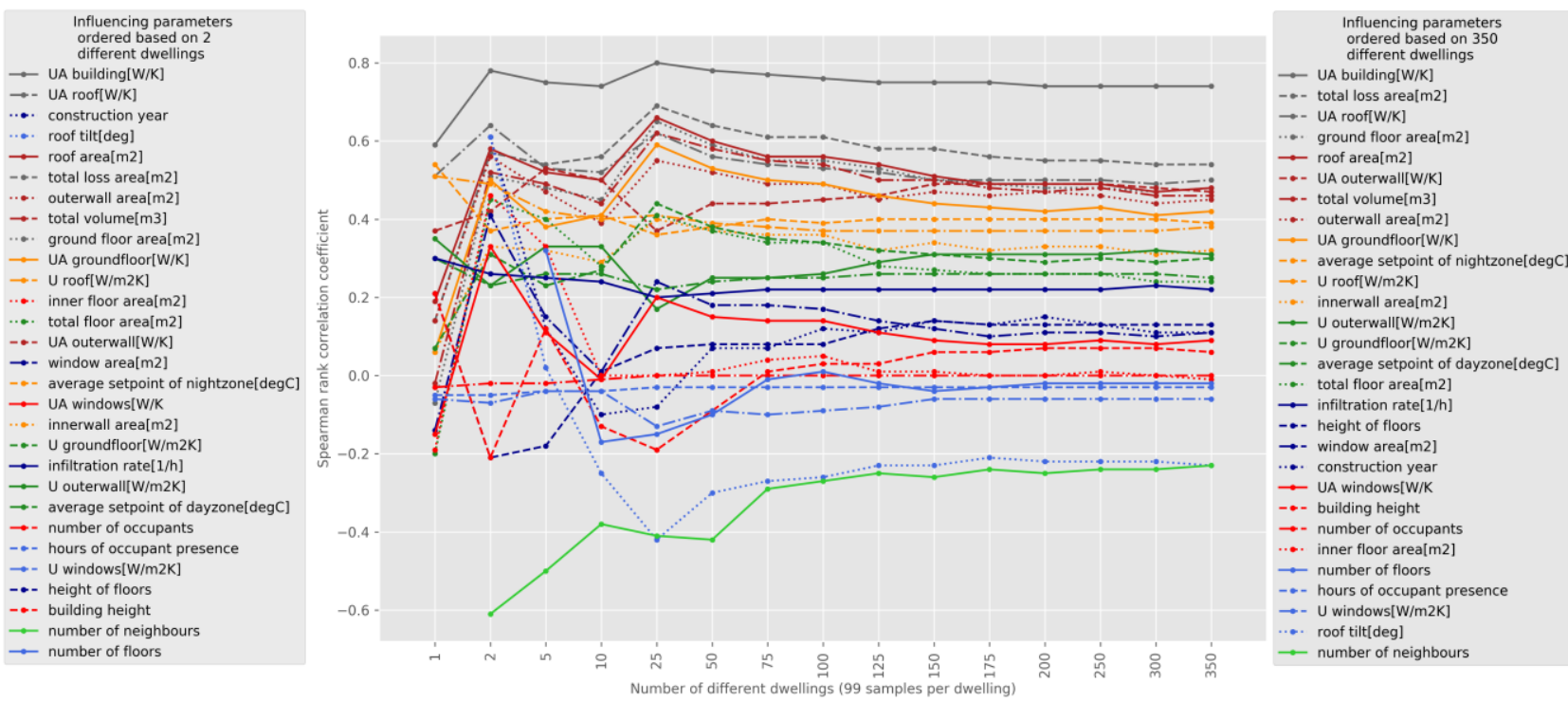

Figure 6: Spearman rank correlation coefficients for the building energy demand as a function of the considered number of different dwellings and their 99 samples. The parameter order for two and 350 different dwellings is shown.

To further analyse this, Figure 5 shows the mean uncertainty on the district energy demand for more district sizes (red line). The mean uncertainty decreases as the district size increases. The largest decrease is situated between 1 and 50 buildings, as the mean uncertainty is reduced from $83.1 \%$ for "districts of 1 building" to $13.5 \%$ for districts of 50 buildings. Additionally, Figure 5 shows the uncertainty on the mean district energy demand of the district samples within one district size (blue line). The trend is very similar to the mean uncertainty. The largest decrease is also situated between 1 and 50 buildings, as the uncertainty of the mean is reduced from $65.3 \%$ for "districts of 1 building" to $10.1 \%$ for districts of 50 buildings.

\section{Sensitivity analysis}

After assessing the uncertainty on the district energy demand for different district sizes, it is also investigated from where the uncertainty on the building energy demand originates for including different numbers of dwellings. To rank the different parameters, the SRCC is employed, as discussed in the previous Section. Figure 6 shows the ranking of the different parameters that impact the building energy demand, for different number of buildings that are included (i.e. if the number of different dwellings is 1, then the SRCCs are calculated for the 99 samples of 1 randomly selected dwelling. For 2 different dwellings, another randomly selected dwelling in its 99 samples is added to the set, and so on. When the number of different dwellings is 100, the SRCCs are thus calculated for the 99 samples of these 100 dwellings and thus based on the results of 9900 building simulations). For the parameters that are not varied per building, but that are included in the sensitivity analysis, the SRCC cannot be calculated if only one building and its samples are considered. Hence, some parameters are only shown from two or three dwellings onwards.

As expected, the ranking shows an unstable behaviour for a small amount of dwellings, but stabilises when more buildings are included. This effect is especially noticed for the most dominant parameters (i.e. the parameters that have a SRCC close to 1 or -1 ). The ranking for two buildings is thus different from the ranking for 350 buildings, as is illustrated in the legend of Figure 6 .

It is also studied to which extent Figure 6 depends on the chosen set of dwellings. For a low number of considered dwellings, the ranking highly depends on the selected set of dwellings, whereas for a higher number of considered dwellings (>100), the ranking is stable and regardless of the selected dwellings. This is also reflected in the pvalues. For a small number of dwellings, the $p$-values are inconclusive for more parameters (depending on the chosen set of dwellings), whereas for a larger number of dwellings, the p-values are only inconclusive for the number of occupants and the inner floor area. This observation is important when e.g. fitting meta-models to predict the building energy demand within existing districts. If only five different buildings and their 99 samples are considered, the dominant parameters depend highly on the selected buildings. To overcome this dependency, at least 100 different buildings and their 99 samples should be included for the studied district, given the assumed uncertainties on the inputs.

The most important parameter regardless of the number of considered dwellings is the UA value of the building. When considering districts of more than 75 different dwellings, the total loss area is the second most influencing parameters, followed by the UA value of the roof, the ground floor area, the roof area, the UA value of the outer wall, the total volume, the outer wall area and the UA value of the ground floor.

The average set-point temperature of the night zone is the first occupant-related parameter that appears in the ranking (at the $10^{\text {th }}$ place). The night zone set-point temperature appears to be more important than the day zone set-point temperature, but the distribution on the night zone is also larger than the distribution on the day 
zone. In fact, according to the StROBe package, $20 \%$ of the residential buildings have a heated night zone, introducing a larger uncertainty on the night zone setpoint compared to the day zone set-point. Additionally, the night zone is often larger than the day zone as the majority of the dwellings have two or three storeys.

The importance of some parameters decreases, as more buildings are included. A first example is the number of neighbours (i.e. adjacent buildings). It is strongly inversely proportional to the building energy demand for a small number of different dwellings, but this effect fades when more dwellings are included. A second example is the average roof tilt. For a large number of dwellings, the average roof tilt is inversely proportional to the building energy demand. A third example is the UA value of the windows. It seems to be important for a small number of dwellings, but its SRCC decreases for a larger number of dwellings.

\section{Discussion}

The scope of this study is to model existing districts and to assess the uncertainty within these models. The methodology and the results should also be seen from this perspective. This work is considered to be a first exploration of the impact of input data uncertainty on the reliability of the district energy demand. However, there are definitely opportunities for improvement in this study, which are discussed here.

First, regarding the variations on the input parameters, 14 parameters are selected and their distribution is intended to be as realistic as possible. The inner floor area and inner wall area in the initial model are based on assumptions and a large range is considered. Although the exact range can be questioned, the influence on the energy demand of the inner wall area is limited following the SRCC, even with the assumed large range. Additionally, the distribution of the number of occupants originates from population statistics for Flanders. The representability of the Flemish distribution for the considered district can be questioned. Additionally, in the present work, a specific occupant profile is sampled following the Sobol' sequence, resulting in 99 different occupant profiles for the 99 samples of 1 building. To add more variability, these 99 profiles per building should change from building to building, which will be implemented in future work.

Also, the correlation between all inputs should be taken into account when sampling, which will be the focus of future work.

Third, regarding the number of considered dwellings, 350 different dwellings and 99 variations of each dwelling are considered. The uncertainty on the district energy demand, as shown in Figure 5, decreases significantly for larger district sizes. However, the variability between the 349 considered district samples is also significantly smaller for larger district sizes, since a district sample is defined through random sampling of the 350 considered dwellings without replacement. Nevertheless, the gradient of the curve in Figure 5 is largest for smaller district sizes, which do not suffer from the limited set of different dwellings. Ideally, more different dwellings and more samples per dwelling should be considered.

Fourth, regarding the selected simulation model, a detailed two-zone model is used in this work, enabling to assess the influence of day zone and night zone temperature separately. Although the use of two-zone models is unique to this work compared to other UAs on the district level, the analysis could be extended by using other building energy models.

Finally, regarding the selected sensitivity index, the Spearman rank correlation coefficient is selected in this work. However, the SRCC does not include interactions between the input variables, possibly resulting in a distorted ranking of important parameters. The sensitivity analysis will be the focus of future work, looking not only at the building energy demand but also at the district energy demand. Among the large amount of possible methods, standardised regression coefficients can be employed. However, to calculate these, the included parameters should not be correlated. To tackle this, different regression models can be fitted (e.g. 1 with the UA value of the building, 1 with the UA values of the components and 1 with all $\mathrm{U}$ and $\mathrm{A}$ values separately).

\section{Conclusion}

This work intends to quantify the uncertainty propagation for the district energy demand of existing districts using realistic variations on input data. In total, 14 parameters are varied, generating 99 building samples for 350 singlefamily dwellings. Subsequently, districts of different sizes are composed from the single buildings. For each district size, 349 randomly selected district samples are considered. For each of these district samples, 99 variations or building samples are considered, resulting in 34551 unique districts per district size.

First, the uncertainty on the district energy demand due to the uncertainty on the input parameters is studied. The mean uncertainty of the district energy demand and the uncertainty on the mean district energy demand of all district samples within one district size both decrease as the district size increases. Comparing "districts of 1 building" to districts of 50 buildings, a reduction is noted from $83.1 \%$ to $13.5 \%$ and from $65.3 \%$ to $10.1 \%$, for the mean uncertainty and the uncertainty of the mean district energy demand respectively.

Second, it is studied from where this uncertainty originates, through analysing the building energy demand for an increasing amount different dwellings and their variations. Studying the sensitivity of the input parameters can serve as a guideline of which aspects should be monitored carefully during data gathering in real case studies. Although a more in-depth sensitivity analysis is part of future work, it is shown that the ranking of the different building parameters following the SRCC changes when including more different dwellings. Based on the assumed input variations in this work, at least 100 different dwellings should be included to obtain a stable parameter ranking and create a reliable meta-model to predict the building energy demand of existing buildings. In this study, the transmission losses are dominant and 
mostly determined by the roof. The SRCC thus indicates for this case that the transmission losses should be gathered as accurately as possible, as they are dominant for the building energy demand within existing districts. Further research is suggested to include the combined impact of the input parameters on the district energy demand.

\section{Acknowledgement}

The main author holds a $\mathrm{PhD}$ grant fundamental research co-financed by the Research Foundation - Flanders (FWO) and the Flemish Institute for Technological Research (VITO) (grant number: 11D0318N). This work emerged from the IBPSA Project 1, an international project conducted under the umbrella of the International Building Performance Simulation Association (IBPSA). Project 1 will develop and demonstrate a BIM/GIS and Modelica Framework for building and community energy system design and operation.

\section{References}

Baetens, R., \& Saelens, D. (2015). Modelling uncertainty in district energy simulations by stochastic residential occupant behaviour. Journal of Building Performance Simulation, 9(4), 431-447.

Callebaut, C., \& Saelens, D. (2018). Optimisation of district energy simulations by means of a tailormade clustering approach. KU Leuven.

Clarke, J. A., \& Hensen, J. L. M. (2015). Integrated building performance simulation: Progress, prospects and requirements. Building and Environment, 91, 294-306.

De Jaeger, I., Lago, J., \& Saelens, D. (2018a). A probabilistic approach to allocate building parameters within district energy simulations. In Proceedings of Urban Energy Simulation Conference 2018. Glasgow, UK.

De Jaeger, I., Reynders, G., Ma, Y., \& Saelens, D. (2018b). Impact of building geometry description within district energy simulations. Energy, 158, 1060-1069.

Gröger, G., \& Plümer, L. (2012). CityGML Interoperable semantic 3D city models. ISPRS Journal of Photogrammetry and Remote Sensing, $71,12-33$.

Hamby, D. M. (1994). A review of techniques for parameter sensitivity analysis of environmental models. Environmental Monitoring and Assessment, 32(2), 135-154.

Hughes, M., Palmer, J., Cheng, V., \& Shipworth, D. (2015). Global sensitivity analysis of England's housing energy model. Journal of Building Performance Simulation, 8(5), 283-294.

Johnson, M. E. E., Moore, L. M. M., \& Ylvisaker, D. (1990). Minimax and maximin distance designs. Journal of Statistical Planning and Inference, 26(2), 131-148.

Jorissen, F., Reynders, G., Baetens, R., Picard, D., Saelens, D., \& Helsen, L. (2018). Implementation and verification of the IDEAS building energy simulation library. Journal of Building Performance Simulation, 11(6), 669-688.

Mastrucci, A., Pérez-López, P., Benetto, E., Leopold, U., Blanc, I., \& Mastrucci, A. (2017). Global sensitivity analysis as a support for the generation of simplified building stock energy models. Energy \& Buildings, $149,368-383$.

Mavromatidis, G., Orehounig, K., \& Carmeliet, J. (2018). Uncertainty and global sensitivity analysis for the optimal design of distributed energy systems. Applied Energy, 214, 219-238.

Mckay, M. D. D., Beckman, R. J. J., \& Conover, W. J. J. (1979). A Comparison of Three Methods for Selecting Values of Input Variables in the Analysis of Output from a Computer Code. Technometrics, 21(2), 239-245.

Metropolis, N., \& Ulam, S. (1949). The Monte Carlo Method. Journal of the American Statistical Association, 44(247), 335-341.

Naber, E., Volk, R., \& Schultmann, F. (2017). From the Building Level Energy Performance Assessment to the National Level: How are Uncertainties Handled in Building Stock Models. Procedia Engineering, 180, 1443-1452.

Nouvel, R., Brassel, K.-H., Bruse, M., Duminil, E., Coors, V., Eicker, U., \& Robinson, D. (2015). SIMSTADT, a New Worflow-driven Urban Energy Simulation Platform for CityGML City Models. In CISBAT 2015, International Conference on Future Buildings \& Districts. Lausanne, Switzerland.

Nouvel, R., Zirak, M., Coors, V., \& Eicker, U. (2017). The influence of data quality on urban heating demand modeling using 3D city models. Computers, Environment and Urban Systems, 64, 68-80.

Remmen, P., Lauster, M., Mans, M., Fuchs, M., Osterhage, T., \& Müller, D. (2018). TEASER: an open tool for urban energy modelling of building stocks. Journal of Building Performance Simulation, 11(1), 84-98.

Sobol', I. M. (1967). Point distribution in a cube and approximate evaluation of integrals. USSR Computational Mathematics and Mathematical Physics, 7(4), 86-112.

Tian, W. (2013). A review of sensitivity analysis methods in building energy analysis. Renewable and Sustainable Energy Reviews, 20, 411-419.

Tian, W., Heo, Y., de Wilde, P., Li, Z., Yan, D., Park, C. S., ... Augenbroe, G. (2018). A review of uncertainty analysis in building energy assessment. Renewable and Sustainable Energy Reviews, 93, 285-301.

Wonen Vlaanderen. (n.d.). Demografische cijfers. Retrieved January 14, 2019, from https://www.wonenvlaanderen.be/woononderzoeken-statistieken/demografische-cijfers. 
